\title{
The Effect of Autogenous Fascia Relaxation and Spinal Mobility Exercise on Pain and Range of Motion in Elderly Female Patients with Chronic Back Pain
}

\author{
${ }^{1}$ Sung-Wan Park ${ }^{\text {D }, ~}{ }^{1}$ Na-Young Yoon ${ }^{D},{ }^{2}$ Mi-Sun Lee ${ }^{D}$, ${ }^{1}$ Je-Hun Lee ${ }^{D}$ * \\ ${ }^{1}$ Anatomy Lab., College of Sports Science, Korea National Sport University, Seoul, South Korea. ${ }^{2}$ School \\ of Music and Arts, College of Music and Arts, Dankook University, Jukjeon, South Korea.
}

Submitted 11 January 2021; Accepted in final form 10 April 2021.

\begin{abstract}
Background. Band exercise can also reduce back pain by reducing unnecessary movement of the thoracic and cervical vertebrae adjacent to the lumbar spine. Looking at previous studies, activation of the deep lumbar muscles of the lumbar spine and restoration of mobility of the adjacent skeleton have a positive effect on pain relief. Objectives. This study was to investigate the effects of self-fascial relaxation, stretching, and spinal mobility exercises using foam rollers and elastic bands on elderly women's back pain, pain disability index, and spinal joint mobility. Methods. This study was performed on elderly women (65-75years) who had no surgical experience within one year, had more than one clinical result due to back pain, and maintained pain for more than 6 months. The subjects who participated in the study were divided into groups, group exercising with foam rollers and elastic bands, group B exercising without foam rollers and elastic bands, and a control. To see the effects of pain-related exercise, we assessed the subjects with the visual analog scale (VAS), Oswestry disability index (ODI), spinal flexion, and the range of spinal left and right joint rotation movement. Results. the decrease in VAS $\left(F=9.976, p=.001, \eta^{2}=.487\right)$ and ODI $\left(F=4.978, p=.017, \eta^{2}=\right.$ .322) was observed in all groups participating in the experiment, and the value of experimental group $A$ using foam roller and elastic band decreased the most. As can be seen from the results of Experimental Group A, where the bending and stiffness of the spine were statistically significantly increased. Conclusion. According to the significant result of $\mathrm{A}$, the use of elastic bands and foam rollers is considered to be effective in improving chronic back pain and mobility of the spine.
\end{abstract}

\section{KEYWORDS: Low Back Pain, Form Roller, Elastic Band, Self-Fascial Relaxation Program.}

\section{INTRODUCTION}

Low back pain is the most common cause of pain in older adults (1). When low back pain becomes chronic in older adults, a number of deleterious con-sequences may result, including falls and fractures (2).

Nearly two-thirds of these patients continue to experience significant pain-related functional impairment a year after initial onset (3). Low back pain is considered "acute" if the pain persistence is less than 6 weeks, "subacute" if more than 6 weeks, and "chronic" if it is longer than 12 weeks.
Only about $1 \%$ of patients experiencing back pain are chronic, and pain reduces the role of muscles and sensory organs (4). The frequency of back pain increases with age and is more prevalent in older women. This is due to decreased muscle mass, increased osteoporosis, and high housework that puts strain on the lower back (5, 6). Fatigue in the muscles and ligaments, the lumbar support system, causes pain around the spine, which reduces movement, unbalances the body, and limits the range of activity, resulting in

*. Corresponding Author:

Je-Hun Lee, Ph.D

E-mail: leejehun@knsu.ac.kr 
decreased muscle mass (7). As chronic low back pain progresses, the intrinsic perception of the ability to turn the lumbar spine to neutral or lower it to a sitting position decreases $(8,9)$. The intensity of the pain depends on the degree of contraction of the fascia that maintains the normal shape of the body, muscles, nerves and skeleton (10). Relying solely on drug formulations and injections as a therapeutic approach to improving back pain can limit flexibility and reduce core strength and spinal durability, resulting in recurrence of pain (11). Fascia Relaxation Exercise, a nerve and fascia system recommended by the National Academy of Sports Medicine (NASM), SMR uses foam rollers and braces to inhibit irritable muscle fibers and to reduce the emotional or physical effects of the autonomic nervous system, such as vasodilation and increased muscle contraction. Relieves stress and increases joint range of motion (12). It is recommended to use a foam roller and an elastic band together to increase flexibility and intensity of exercise, as applying SMR before exercise reduces muscle stiffness and muscle fatigue, resulting in smoother activity (13). Elastic bands stimulate the intrinsic receptive sensations of joints and muscles, and communicate information about joint position and movement to the brain to help maintain correct posture. The elastic level of the band is adjustable, making it suitable for rehabilitation or exercise programs for the elderly (14). Resistance exercises with elastic bands may also help stabilize the lower back by improving local muscle problems and enabling closed-chain exercises that make more movement in key muscle areas (15).

Band exercise can also reduce back pain by reducing unnecessary movement of the thoracic and cervical vertebrae adjacent to the lumbar spine (16). Looking at previous studies, activation of the deep lumbar muscles of the lumbar spine and restoration of mobility of the adjacent skeleton have a positive effect on pain relief (17). Therefore, we would like to study whether the use of local and deep muscle stimulating factors stabilizes the lower back and improves the overall movement and function of patients with chronic low back pain.

\section{MATERIALS AND METHODS}

Characteristics. The study recruited, elderly women aged 65 to 75 years old who have been diagnosed with low back pain in a hospital and are currently experiencing low back pain for at least
6 months. Those who underwent surgery last year or are currently receiving treatment at the hospital and those with too little pain (less VAS 2) were excluded from the experiment. The selected 24 people were divided into 3 groups of 8 each according to their age and pain level. Self-facial relaxation and stretching with foam rollers and elastic bands, spinal exercise exercises (experimental group A), a group that performed stretching and spinal exercises without props (experimental group B) and applied group stretching (control) were selected. Prior to commencement, all subjects were informed of the purpose and process of the study and voluntarily agreed to participate in the program. After completing VAS and ODI to see the participant's pain level and spinal mobility, an inclinometer was used to measure the flexion and extension of the thoracic spine, and a goniometer was used to measure the axial rotation of the thoracic spine. The exercise programs of experimental group A and experimental group $\mathrm{B}$, and stretching of the control group were performed 5 times a week for 5 weeks for each group in Table 1.

Exercise Programs. The basic exercise programs of Experiment Groups A and B consisted of warm-up, main, and rearranging exercises, and the duration of the program was 30 minutes in total, five times a week for five weeks, under the guidance and supervision of the researcher. Before starting the exercise, we helped the participants to understand the exercise through pre-training and direct motion demonstration of the program.

Preparatory exercise and self-fascial relaxation program in experimental groups $\mathrm{A} \&$ B. Groups A and B performed the same warm-up routines. Group A used a foam roller, and B did not use a foam roller. In addition, the self-fascial relaxation program applied to experimental Group A was constructed based on the content of the application guidelines for relaxation fascia, an orthodontic exercise training essential to NASM. Group A's preparatory exercises are to repeat the thoracolumbar fascial release by using a foam roller, thoracic three-dimensional release, thoracic flexion, and thoracic extension movements for five minutes. Group B warm-up is to perform chest expansion, chest flexion, chest rotation, curling, and lying spine stretching for five minutes in a sitting position without using a foam-roller. The detailed contents are organized as shown in Table 2. 
Main exercise and spinal movement exercise program of experimental group $\mathrm{A}$ and $\mathrm{B}$. The program to increase the mobility of the spine used in this study was constructed after considering the characteristics of the elderly participants. Therefore, during the lateral rotation of the lumbar spine, the rotation of the skeleton was restricted by applying a reverse oscillation position where the hips were bent over 90 degrees (13). Intensity was applied according to each performance ability within the pain-free range (40-60\% of the maximum strength) as the age group of participants was high.

The main movement was performed in the same motion, group A applied an elastic band, and group B performed without an elastic band. The detailed contents are organized as shown in Table 2.

Cool down exercise program of experimental group $\mathrm{A}$ and $\mathrm{B}$. For the rearranging movement, Pilates' saw, bending, and shock movements using a three-dimensional spinal movement were applied to the yoga cat-cow movement, along with breathing (18). Both experimental groups A and B used the same cooldown program, and experimental group B proceeded without an elastic band. The details are organized as shown in Table 2.

Control group stretching program. Strengthening and stretching were applied in accordance with each individual's level of physical health and flexibility, according to their characteristics. The duration of these was applied in the same way as in the experimental group. Stretching the areas was performed with torso flexion and extensor muscles, broad back muscles, bulge muscles, thigh muscles, hip muscles, and lumbar muscles. The detailed contents are organized as shown in Table 3.

Variable and Tools. VAS Assessment. We used the VAS to investigate the decrease in pain levels as a result of the study. After dividing the degree of pain subjectively from 0 to 10 , the degree of pain was calibrated by setting the degree of painlessness at 0 and the degree of unbearable pain at 10 . Reliability is $r=0.97(18$, 19).

ODI Assessment. The ODI is based on the Korean version of the Oswestry Back Pain Disability Index (KODI) produced in Korea (20). The evaluation table was reorganized by modifying some of the items. Pain level, selfmanagement status, object lifting, walking, sitting, standing, sleeping, social life, travel, and movement encompasses a total of 10 questions covering whether there is pain or no pain, depending on the performance of the subject. The lower the score is, the less physical disability there is that is caused by back pain. KODI's testretest reliability is high, with $\mathrm{r}=0.92$ (17).

Measurement of Thoracic Vertebrae Extension and Flexion Range of Movement (ROM). In order to measure the extension and flexion of the spine in the study, we used the inclinometer measurement method with a high reliability of $r=0.93$ to 0.95 (19). The patient's hips and knees were bent in a 90-degree position, sitting in the middle of the chair.

We took measurements of the subjects with two inclinometers after they had been allowed to operate in the maximum range of bending and impact. We placed the inclinometer in the visible process between thoracic vertebra 1 and 2, and another in the visible process between thoracic vertebra 12 and lumbar vertebra 1, adding a number to the inclinometer and the number in front of the spine. We measured kyphosis values three times and analyzed these as an average value shown in Figure 1 and Table 2.

Measurement of the Rotation ROM of the Thoracic Vertebrae. In the study, the measurement posture that was used to find the range of rotation showed a high reliability ( $\mathrm{r}=$ 0.85 to 0.94$)$. In the same manner as in the extension-flexion test, the subjects minimized the movements of the hip and lumbar spine by adding a mini-ball between the knees and bringing the legs together to hold the mini-ball.

After crossing the X-types, each was placed on the opposite shoulder, and in this state a wooden bar was placed on the shoulder. After placing the goniometer between $1 \mathrm{st}$ and 2 nd spinous processes of thoracic vertebra and adjusting the zero point, the angle of rotation was measured three times in each direction from side to side, and the angles of left and right rotation were summed and analyzed as an average value shown in Figure 2 and Table 2.

Statisical Analysis. All data obtained from this study was calculated by using Microsoft Office Excel 2016 software (Microsoft Corporation, Redmond, WA, USA) to calculate descriptive statistics (Mean $\pm \mathrm{SD}$ ). In addition, before and after the application of each group, bidirectional two-way repeated measurement ANOVA was performed to check the difference 
between ODI, VAS, spinal bending, spine, and left and right rotation ROM, and we utilized SPSS 21.0 (SPSS Science, SPSS Science, Chicago, USA). At this time, the statistical significance level was set to $\alpha=0.05$

\section{RESULTS}

VAS. As a result of performing an analysis of variance of VAS over group and time, the effect of time and group interaction on VAS was statistically significant with $\mathrm{F}=9.976, \mathrm{P}=0.001$, $\eta^{2}=0.487$, as shown in Table 4 .

ODI. As a result of analysis of variance of ODI by group and period, the effect of interaction between period and group was statistically significant and can be seen in Table 4 as $\mathrm{F}=$ 4.978, $\mathrm{P}=0.017, \eta^{2}=0.322$. The intra-group difference of 5.00, the control group (before: $11.13 \pm 6.24$, after: $10.25 \pm 7.85$ ) showed the greatest difference in experimental group A with a difference of 0.87 within the group. Details can be found in the Table 4 .

ROM of Flexion. As a result of the analysis of variance of the range of motion of the spinal flexor according to the group and time, the effect of time and group interactions on the range of motion of the spinal flexion was statistically shown $\left(\mathrm{F}=.532, \mathrm{P}=0.595, \eta^{2}=0.048\right)$ Table 5 There were no significant differences. However, when comparing the mean value difference, the difference in experimental group A was $5.75^{\circ}$, which was the only increase among the three groups. The results are shown in Table 5.

ROM of Extension. As a result of analysis of variance for groups and time of spinal range of motion, the effect of time and group interactions on spinal range of motion $(\mathrm{F}=1.305, \mathrm{P}=0.292$, $\eta^{2}=0.111$ ) was not statistically significant. However, when comparing the mean value difference, the difference between the groups in experimental group A was $5.75^{\circ}$, which was the only increase among the three groups. The results are presented in Table 5.

ROM of Rotation. As a result of analysis of variance on the range of spine left and right rotation according to the group and time, when comparing the difference between the mean values, experimental group A (previously: $78.75^{\circ} \pm 14.07$, post: $108.75^{\circ} \pm 20.28$ ) had a $30.0^{\circ}$ difference between groups, and experimental group B (experimental group B (Previous: $101.0^{\circ} \pm 17.72$ : $\left.105.13^{\circ} \pm 16.58\right)$ There was a $4.12^{\circ}$ difference between groups. In the case of the control group (before: $88.67^{\circ} \pm 17.88$, post: $74.38^{\circ} \pm 16.32$ ), the difference between groups was $-11.87^{\circ}$, which was the largest difference in experimental group $\mathrm{A}$. The results are shown in Table 5.

Table 1. Characteristics of Subjects

\begin{tabular}{lccc}
\hline & Group A & Group B & Group C \\
\hline Age (years) & $68.25 \pm 2.86$ & $70.00 \pm 3.02$ & $68.37 \pm 3.77$ \\
Height (cm) & $157.25 \pm 5.89$ & $158.87 \pm 5.51$ & $157.86 \pm 4.12$ \\
Weight $(\mathbf{k g})$ & $57.00 \pm 4.40$ & $57.25 \pm 5.59$ & $54.81 \pm 4.10$ \\
\hline
\end{tabular}

Table 2. Thoracic Mobility Exercise Program

\begin{tabular}{lcc}
\hline Week & Group A\&B & Duration (minute) \\
\hline $\mathbf{1 ~ 5}$ - & & \\
Warm up & Thoracic self-release, Thoracic three dimensional Curl up(crunch), Lying spine stretch & 5 \\
Main & Hug a tree \& thoracic rotation, Spine stretch, Rolldown \& Roll up, Back extension \& & 25 \\
& Swandive, Quadruped Heel Sit Thoracic Ext/Rot, Seated Trunk Rotation, Swimming & \\
Cool down & \& Swan dive, Side Lying T-spine Ext/Rot & 5 \\
\hline
\end{tabular}

Group A: mobility exercise using foam roller and elastic band, Group B: only exercise

Table 3. Stretching Program of Control Group C

\begin{tabular}{lcc}
\hline Week & Stretching & Duration (minute) \\
\hline $\begin{array}{c}\text { 1 3 } \\
\text { Warm up }\end{array}$ & $\begin{array}{c}\text { 1. Side bend in sitting position, 2. Forward bending in sitting position, 3. Trunk } \\
\text { rotation stretching in sitting position with open legs, Pilates's Roll down \& Roll up in } \\
\text { standing position, }\end{array}$ & 5 \\
Main & $\begin{array}{c}\text { 1. Iliopsoas stretching in supine \& kneeling position, 2. Hamstring stretching in } \\
\text { supine \& sitting position, 3. Pigeon position, 3. Gluteus stretching in supine position, } \\
\text { 4. Abdominal stretching in prone position, 5. Quadratus lumborum stretching in side } \\
\text { sitting position, 6. Cat \& Cow position }\end{array}$ & 20 \\
Cool down & Trunk Ext/Rot in side \& in quadruped lying position & 5 \\
\hline
\end{tabular}


Table 4. Results of the Two-Way Repeated Measures ANOVA for VAS \& ODI

\begin{tabular}{lccccccc}
\hline Categories & $\mathbf{A}$ & $\mathbf{B}$ & $\mathbf{C}$ & & $\mathbf{F}$ & $\mathbf{P}$ & $\boldsymbol{\eta}^{\mathbf{2}}$ \\
\hline VAS & & & & & & \\
Pre post & $6.38 \pm 2.45$, & $5.38 \pm 1.92$, & $4.56 \pm 1.50$, & $\mathrm{T} \mathrm{G} \mathrm{T}^{*} \mathrm{G}$ & 63.098, & $<0.001$, & $0.750,0.007$, \\
& $2.00 \pm 2.00$ & $3.38 \pm 1.77$ & $3.50 \pm 1.83$ & & $0.075,9.976$ & $0.928,0.001$ & 0.487 \\
ODI & & & & & & & \\
Pre post & $12.50 \pm 4.31$, & $11.50 \pm 5.15$, & $11.13 \pm 6.24$, & $\mathrm{T} \mathrm{G} \mathrm{T}^{*} \mathrm{G}$ & 26.119, & $<0.001$, & $0.554,0.030$, \\
& $4.88 \pm 5.06$ & $6.50 \pm 5.32$ & $10.25 \pm 7.85$ & & $0.324,4.978$ & $0.727,0.017$ & 0.322 \\
\hline
\end{tabular}

Values are (Mean $\pm \mathrm{SD}) * \mathbf{A}=\operatorname{experimental}$ group $\mathbf{A} ; \mathbf{B}=\operatorname{experimental}$ group $\mathbf{B} ; \mathbf{C}=$ control group; $\mathbf{T}=\operatorname{time}, \mathbf{G}=\mathrm{group} ; \mathrm{T} * \mathrm{G}=$ interaction effect; $F=F$ statistic; $p=p$-values; $\eta^{2}=$ Eta squared, $M=$ Mean; $S D=$ Standard Deviation

Table 5. Results of the Two-Way Repeated Measures ANOVA for Thoracic Flexion

\begin{tabular}{|c|c|c|c|c|c|c|c|}
\hline Categories & A & B & C & & $\mathbf{F}$ & $\mathbf{P}$ & $\eta^{2}$ \\
\hline \multicolumn{8}{|c|}{ Thoracic/Flex } \\
\hline Pre post & $\begin{array}{l}41.63 \pm 15.97 \\
47.38 \pm 12.69\end{array}$ & $\begin{array}{l}42.38 \pm 12.12 \\
37.13 \pm 13.94\end{array}$ & $\begin{array}{c}48.75 \pm 15.29 \\
46.63 \pm 8.68\end{array}$ & $\mathrm{TGT}^{*} \mathrm{G}$ & $\begin{array}{c}0.015,2.237, \\
0.532\end{array}$ & $\begin{array}{c}0.905,0.132, \\
0.595\end{array}$ & $\begin{array}{c}0.001,0.176, \\
0.048\end{array}$ \\
\hline \multicolumn{8}{|c|}{ Thoracic/Ext } \\
\hline Pre post & $\begin{array}{l}29.25 \pm 15.63 \\
35.00 \pm 12.32\end{array}$ & $\begin{array}{l}38.63 \pm 23.72 \\
34.88 \pm 24.69\end{array}$ & $\begin{array}{l}23.75 \pm 15.33 \\
23.50 \pm 11.38\end{array}$ & $\mathrm{TGT}^{*} \mathrm{G}$ & $\begin{array}{c}0.058,1.236 \\
1.305\end{array}$ & $\begin{array}{c}0.813,0.311, \\
0.292\end{array}$ & $\begin{array}{c}0.003,0.105, \\
0.111\end{array}$ \\
\hline \multicolumn{8}{|l|}{ Thoracic/Rot } \\
\hline Pre post & $\begin{array}{c}78.75 \pm 14.07 \\
108.75 \pm 20.28 \\
\end{array}$ & $\begin{array}{c}101.0 \pm 17.72 \\
105.13 \pm 16.58 \\
\end{array}$ & $\begin{array}{l}86.25 \pm 17.88 \\
74.38 \pm 16.32\end{array}$ & $\mathrm{TGT}^{*} \mathrm{G}$ & $\begin{array}{c}3.302,5.301, \\
8.935 \\
\end{array}$ & $\begin{array}{c}0.083,0.014, \\
0.002\end{array}$ & $\begin{array}{c}0.136,0.335, \\
0.460\end{array}$ \\
\hline
\end{tabular}

Values are (Mean $\pm \mathrm{SD}) * \mathrm{~A}=$ experimental group $\mathrm{A} ; \mathrm{B}=\operatorname{experimental}$ group $\mathrm{B} ; \mathrm{C}=$ control group; $\mathrm{T}=$ time, $\mathrm{G}=\mathrm{group} ; \mathrm{T} * \mathrm{G}=$ interaction effect; $F=F$ statistic; $p=p$-values; $\eta^{2}=$ Eta squared, $M=$ Mean; $S D=$ Standard Deviation

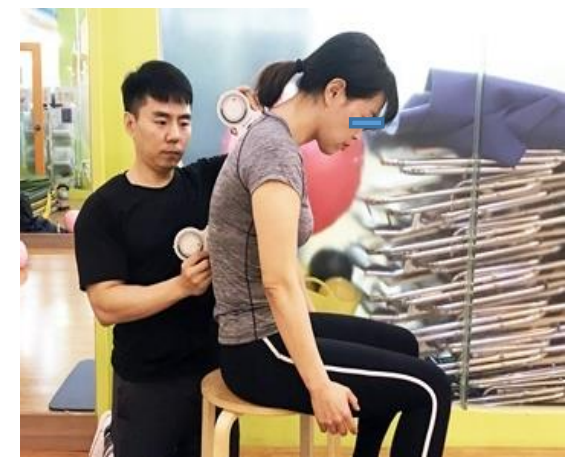

a. thoracic flexion

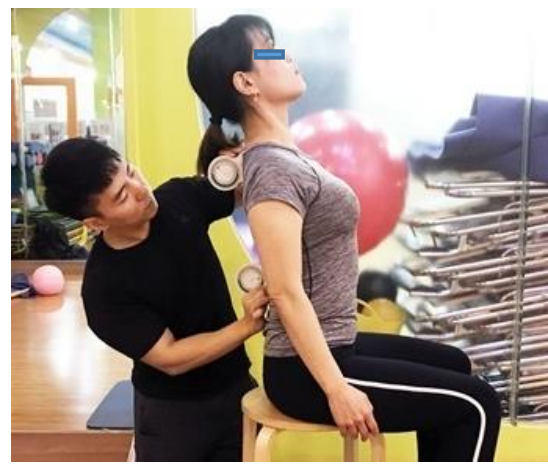

b. thoracic extension

Figure 1. Measurement of the Thoracic Vertebrae Used Inclinometer.

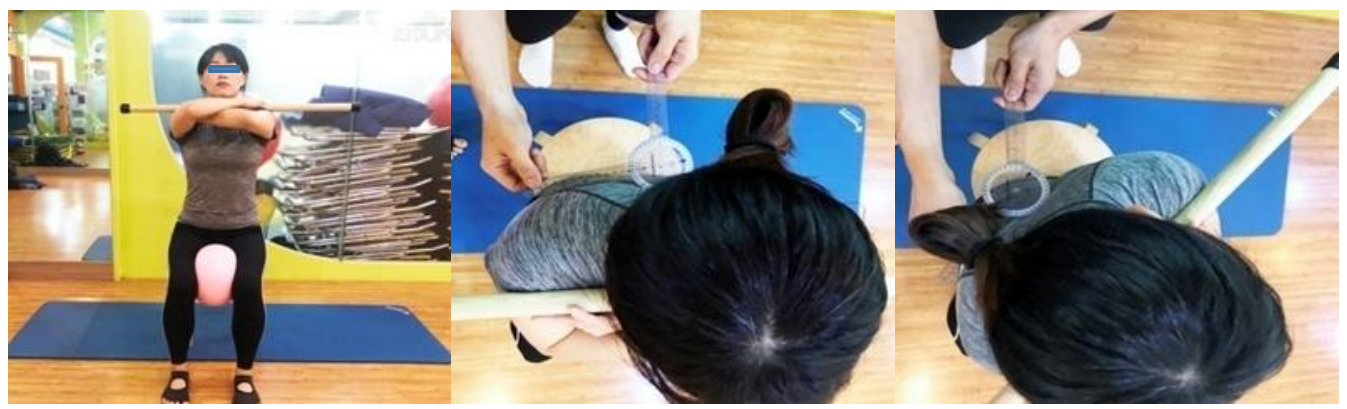

Figure 2. Measurement of the Thoracic Vertebrae Rotation Used Goniometer

\section{DISCUSSION}

To date, various therapeutic exercise methods have been used to relieve pain in patients with chronic low back pain, and many studies have been reported. Another study divided 120 people in their 20s to 50s into an exercise group and a physiotherapy group to check the degree of pain reduction between the 
groups, and the pain reduction in the exercise group was much higher. In another study, the lower back pain index, lower back muscle strength, lower back stability index, and weight distribution index in patients who had suffered hip pain for between 30 to 50 years were effectively treated with hip stabilization exercise $(21,22)$. As a related study, in the study of ODI reduction and lumbar alignment, stabilization exercise was applied to only one group after applying stabilization exercise to all 30 patients with chronic low back pain, and as a result, ODI of the exercise application group was decreased (23). In this study, the exercise programs encompassing Experimental Groups $\mathrm{A}$ and $\mathrm{B}$ consisted of exercises that increased the mobility of the spine. Experimental group A members, who had more effective pain relief, used elastic bands for the same exercise. Elastic bands have a positive effect on maintaining correct posture and developing body balance. They are helpful in increasing spinal mobility and restoring functional stability to the lumbar spine. In addition, holding the elastic band between the hands and feet and using that for exercising results in a closed kinetic chain movement with predominantly closed force and centrifugal contraction. Closed-chain exercises help improve segmental inter- and intracoordination and increase waist stability by mobilizing more muscles in the core area. Therefore, the authors think that the result of experiment group A, which significantly reduced back pain after application of the program, proved the effectiveness of spine mobility exercises using an elastic band (24, 25). SMR has traditionally been used as a supplement to the treatment of soft tissue injuries. Adhesion and dysfunction of soft tissue can cause pain by changing the dynamics of the surrounding joints. Therefore, SMR using foam rollers helps to treat injuries by applying pressure to soft tissues by varying the body position and carrying weight (26). In a previous study of using SMR for pain reduction, delayed leg muscle pain was reduced in eight healthy men who had done SMR for 20 minutes by using a foam roller immediately following a back squat exercise (27). In addition, using a foam roller for SMR immediately following exercise in 20 men who had had muscle training for greater than three years was effective in reducing muscle pain (28). As in the previous study, this study shows that the average difference in experimental group A's range of vertebral joint motion is the largest when compared to the other groups. Thus this study leads us to believe that SMR with stretching and foam rollers helps to increase the range of joint movement. For experimental group A, SMR was applied to the entire backbone, including the thoraco-lumbar junction, thus affecting the increased shear strain of the dorsal fascia. Since the dorsal fascia and the backbone are connected through the fascia, it is thought that the range of motion of the backbone joint increased. In this study, elastic bands were used in experimental group A for stretching and spine mobility exercises with a low resistance of about $1.7 \mathrm{~kg}$ to $2.5 \mathrm{~kg}$ at $100 \%$ to $200 \%$ elongation, in accordance with the individual characteristics of the participants. Since experimental group A's mean difference between the left and right rotational joint motion range was larger when compared to the other groups, the program of experimental group A, which had used elastic bands, was considered to have significantly improved spine ROM than had the experimental B program, which did not use elastic bands.

As can be seen from the results of experimental group $\mathrm{A}$, which showed a statistically significant increase in bending and stiffness of the spine, foam rollers and elastic bands stimulate the intrinsic water-soluble sensation, thereby conveying information on the position and movement of the joint to the cerebrum to help maintain accurate posture. This seems to be possible (14). Therefore, it is thought that the use of elastic bands and the foam rollers in the experimental group A influenced the improvement of the cognitive awareness of the backbone and an increase in mobility. There was no difference between experimental group $B$ and the control group, but in experimental group A, there is a difference in the joint motion range between anterior and posterior spine flexion and the knee. There was a difference in the type of exercise, but it was inconsistent with the study results, which reported an increased range of motion in spine bending and joints (29). Considering that the participants' ages were 65 years or greater, it is thought that there will be some limitations in recognizing and performing pure bending of the spine. It is expected that a criterion and a follow-up study to accurately measure the spine's range of motion while 
limiting the movement of the adjacent neck and backbones will be necessary.

\section{CONCLUSION}

The women aged 65 years or greater who had more effective pain relief used elastic bands for the same exercise; it positively affected maintaining correct posture and developing body balance. Also, the average difference in the experimental group who had self-facial relaxation and stretching with foam rollers and elastic bands, spinal exercise exercises, the range of vertebral joint motion is the largest compared to the other groups that performed stretching and spinal exercises without props, and applied group stretching.

\section{APPLICABLE REMARKS}

- Adult women with low back pain during the current six months can use elastic bands for maintaining correct posture and developing body balance. They help increase spinal mobility and restore functional stability to the lumbar spine.

\section{ACKNOWLEDGMENT}

We have not received any financial support from any organization in writing this paper, and no relationship could affect the paper.

\section{REFERENCES}

1. Patel KV, Guralnik JM, Dansie EJ, Turk DC. Prevalence and impact of pain among older adults in the United States: findings from the 2011 National Health and Aging Trends Study. Pain. 2013;154(12):2649-2657. doi: 10.1016/j.pain.2013.07.029 pmid: 24287107

2. Leveille SG, Jones RN, Kiely DK, Hausdorff JM, Shmerling RH, Guralnik JM, et al. Chronic musculoskeletal pain and the occurrence of falls in an older population. JAMA. 2009;302(20):2214-2221. doi: 10.1001/jama.2009.1738 pmid: 19934422

3. Rundell SD, Sherman KJ, Heagerty PJ, Mock CN, Jarvik JG. The clinical course of pain and function in older adults with a new primary care visit for back pain. J Am Geriatr Soc. 2015;63(3):524-530. doi: 10.1111/jgs.13241 pmid: 25754841

4. Meerding WJ, Bonneux L, Polder JJ, Koopmanschap MA, van der Maas PJ. Demographic and epidemiological determinants of healthcare costs in Netherlands: cost of illness study. BMJ. 1998;317(7151):111-115. doi: 10.1136/bmj.317.7151.111 pmid: 9657785

5. Bingefors K, Isacson D. Epidemiology, co-morbidity, and impact on health-related quality of life of selfreported headache and musculoskeletal pain--a gender perspective. Eur J Pain. 2004;8(5):435-450. doi: 10.1016/j.ejpain.2004.01.005 pmid: 15324775

6. Edmond SL, Felson DT. Function and back symptoms in older adults. J Am Geriatr Soc. 2003;51(12):1702-1709. doi: 10.1046/j.1532-5415.2003.51553.x pmid: 14687347

7. Lee PK. Defining physiatry and future scope of rehabilitation medicine. Ann Rehabil Med. 2011;35(4):445-449. doi: 10.5535/arm.2011.35.4.445 pmid: 22506158

8. Gill KP, Callaghan MJ. The measurement of lumbar proprioception in individuals with and without low back pain. Spine (Phila Pa 1976). 1998;23(3):371-377. doi: 10.1097/00007632-199802010-00017 pmid: 9507628

9. Taimela S, Kankaanpaa M, Luoto S. The effect of lumbar fatigue on the ability to sense a change in lumbar position. A controlled study. Spine (Phila Pa 1976). 1999;24(13):1322-1327. doi: 10.1097/00007632-199907010-00009 pmid: 10404574

10. Cleary JP, Walsh DM, Hofmeister JJ, Shankar GM, Kuskowski MA, Selkoe DJ, et al. Natural oligomers of the amyloid-beta protein specifically disrupt cognitive function. Nat Neurosci. 2005;8(1):79-84. doi: 10.1038/nn1372 pmid: 15608634

11. Saur P, Koch D, Steinmetz U, Straub A, Ensink FB, Kettler D, et al. [Isokinetic strength of lumbar muscles in patients with chronic backache]. Z Orthop Ihre Grenzgeb. 1997;135(4):315-322. doi: 10.1055/s-2008-1039395 pmid: 9381768

12. Kalichman L, Ben David C. Effect of self-myofascial release on myofascial pain, muscle flexibility, and strength: A narrative review. J Bodyw Mov Ther. 2017;21(2):446-451. doi: 10.1016/j.jbmt.2016.11.006 pmid: 28532889

13. Mohr AR, Long BC, Goad CL. Effect of foam rolling and static stretching on passive hip-flexion range of motion. J Sport Rehabil. 2014;23(4):296-299. doi: 10.1123/jsr.2013-0025 pmid: 24458506 
14. McCarthy LH, Bigal ME, Katz M, Derby C, Lipton RB. Chronic pain and obesity in elderly people: results from the Einstein aging study. J Am Geriatr Soc. 2009;57(1):115-119. doi: 10.1111/j.15325415.2008.02089.x pmid: 19054178

15. Rademeyer I. Manual therapy for lumbar spinal stenosis: a comprehensive physical therapy approach. Physic Med Rehabilit Clinic. 2003;14(1):103-110. doi: 10.1016/s1047-9651(02)00077-3

16. Nachemson AL. Newest knowledge of low back pain: a critical look. Clinic Orthopedic Related Res. 1985;279:8-20. doi: 10.1097/00003086-198511000-00031

17.Jeon CH, Kim DJ, Kim DJ, Lee HM, Park HJ. Cross-cultural adaptation of the Korean version of the Oswestry Disability Index (ODI). J Korean Societ Spine Surgery. 2005;12(2):146-152. doi: 10.4184/jkss.2005.12.2.146

18.Lucertini F, Gervasi M, D'Amen G, Sisti D, Rocchi MBL, Stocchi V, et al. Effect of water-based recovery on blood lactate removal after high-intensity exercise. PLoS One. 2017;12(9):e0184240. doi: 10.1371/journal.pone.0184240 pmid: 28877225

19. Bijur PE, Silver W, Gallagher EJ. Reliability of the visual analog scale for measurement of acute pain. Acad Emerg Med. 2001;8(12):1153-1157. doi: 10.1111/j.1553-2712.2001.tb01132.x pmid: 11733293

20.Lewis JS, Valentine RE. Clinical measurement of the thoracic kyphosis. A study of the intra-rater reliability in subjects with and without shoulder pain. BMC Musculoskelet Disord. 2010;11:39. doi: 10.1186/1471-2474-11-39 pmid: 20193055

21.Tae-sung K, Ho-bal J, Jung-ah K. The effect of spine joint operation on pain, disability index, and spinal mobility in chronic low back pain patients. Special Educat Rehabilitat Sci Res. 2009;48(2):115-137. doi: 10.12674/ptk.2015.22.3.001

22. Akhtar MW, Karimi H, Gilani SA. Effectiveness of core stabilization exercises and routine exercise therapy in management of pain in chronic non-specific low back pain: A randomized controlled clinical trial. Pak J Med Sci. 2017;33(4):1002-1006. doi: 10.12669/pjms.334.12664

23.Jeong UC, Sim JH, Kim CY, Hwang-Bo G, Nam CW. The effects of gluteus muscle strengthening exercise and lumbar stabilization exercise on lumbar muscle strength and balance in chronic low back pain patients. $J$ Phys Ther Sci. 2015;27(12):3813-3816. doi: 10.1589/jpts.27.3813 pmid: 26834359

24.Page P, Ellenbecker TS. The scientific and clinical application of elastic resistance. Human Kinetics, Champaign, United States2003.

25. George J, Davis BC, Heiderscheid RM, Jennifer N. The scientific and clinical rationale for the integrated approach to open and closed kinetic chain rehabilitation. Orthoped Physic Therap Clinic North America. 2000;9:247-267.

26. Woo SD, Kim TH. The effects of lumbar stabilization exercise with thoracic extension exercise on lumbosacral alignment and the low back pain disability index in patients with chronic low back pain. $J$ Phys Ther Sci. 2016;28(2):680-684. doi: 10.1589/jpts.28.680 pmid: 27065563

27. Curran PF, Fiore RD, Crisco JJ. A comparison of the pressure exerted on soft tissue by 2 myofascial rollers. J Sport Rehabil. 2008;17(4):432-442. doi: 10.1123/jsr.17.4.432 pmid: 19160916

28.Pearcey GE, Bradbury-Squires DJ, Kawamoto JE, Drinkwater EJ, Behm DG, Button DC. Foam rolling for delayed-onset muscle soreness and recovery of dynamic performance measures. $J$ Athl Train. 2015;50(1):5-13. doi: 10.4085/1062-6050-50.1.01 pmid: 25415413

29. Macdonald GZ, Button DC, Drinkwater EJ, Behm DG. Foam rolling as a recovery tool after an intense bout of physical activity. Med Sci Sports Exerc. 2014;46(1):131-142. doi: 10.1249/MSS.0b013e3182a123db pmid: 24343353 